\title{
Comparison of Delorme-Thiersch Operation Outcomes in Men and Women With Rectal Prolapse
}

\author{
Keehoon Hyun, Seo-Gue Yoon \\ Department of Surgery, Seoul Song Do Hospital, Seoul, Korea
}

Purpose: The laparoscopic rectopexy has become increasingly popular with verified stability, surgical route selection should be tailored to individual patient characteristics rather than operative risk. The perineal approach is useful in young male patients who need to preserve fertility. This study aimed to compare the characteristics of men and women who underwent Delorme-Thiersch procedures and analyze the postoperative outcomes of the perineal approach by sex.

Methods: We retrospectively reviewed the medical records of 293 patients who underwent Delorme-Thiersch operations in Seoul Song Do Colorectal Hospital between January 2011 and September 2017. Patient clinical characteristics and postoperative complications were analyzed by sex. We analyzed surgical outcomes with preoperative and 3-month postoperative incontinence questionnaires, constipation levels, and anal manometry.

Results: In this study, men with rectal prolapse were younger than women with the same condition. American Society of Anesthesiologists physical status classifications were higher in women and women had more L-spine X-ray and pudendal nerve terminal motor latency test abnormalities. Anorectal manometry pressures were higher in men. Men also had longer operation times and hospital stays and more postoperative complications ( $8 \mathrm{~T}$ ring infections, 6 patients with bleeding, 3 with strictures, 2 with severe pain, and 2 with rectal perforations). The recurrence rate was higher among women. Conclusion: Men with rectal prolapse were younger, healthier, and had relatively better anorectal function than women. The Delorme-Thiersch operation in men promoted lower recurrence rates and was advantageous in preserving the fertility of young patients, but the incidence of complications was also higher in men. Adequate counseling and preparation for the possibility of complications are needed.

Keywords: Rectal prolapse; Delorme's procedure; Thiersch's procedure; Surgical outcome

\section{INTRODUCTION}

Rectal prolapse is a socially debilitating disorder. The treatment of choice is surgical correction. Reports of more than a 100 surgical procedures have been published; however, there is a lack of consensus as to the optimal procedure [1]. Traditionally, the perineal approach has been chosen for older, high-risk patients because of

Received: September 14, 2018 - Accepted: October 15, 2018

Correspondence to: Seo-Gue Yoon, M.D.

Department of Surgery, Seoul Song Do Hospital, 78 Dasan-ro, Jung-gu,

Seoul 04597, Korea

Tel: +82-2-2250-7368, Fax: +82-2-2233-8528, E-mail: seogue@naver.com ORCID code: https://orcid.org/0000-0001-7770-758X

(C) 2019 The Korean Society of Coloproctology

This is an open-access article distributed under the terms of the Creative Commons Attribution NonCommercial License (http://creativecommons.org/licenses/by-nc/4.0) which permits unrestricted noncommercial use, distribution, and reproduction in any medium, provided the original work is properly cited. fewer surgical complications, less pain, and short hospital stays [2]. The development of minimally-invasive techniques in the treatment of rectal prolapse has been a turning point in the process of selecting the optimal procedure. The laparoscopic approach to rectal prolapse has become increasingly popular since it was described in 1992 [3]. Some studies have reported that laparoscopic rectopexy was associated with less postoperative pain, faster recovery, and lower recurrence rates than open rectopexy [4]. According to Young et al. [5], there were no significant differences in risk-adjusted morbidity between the perineal and laparoscopic approaches. According to a recently published randomized trial, no significant difference in recurrence rates was found between the abdominal approach and perineal approach groups [6]. Therefore, the previous strategy for determining the surgical method based on patient surgical risk requires adjustment according to advances in laparoscopic techniques.

A tailored surgical approach based on patient characteristics is 
preferable to an approach based on patient surgical risk. The prevalence of rectal prolapse in Korea is different from that in Western countries with more elderly female patients. Korea has a higher percentage of younger male patients than in Western countries [7]. However, there are few studies evaluating rectal prolapse treatment in young male patients. The perineal approach is useful in young male patients who need to preserve fertility because it leaves no mesh in the pelvic cavity. Unfortunately, reports on the perineal approach in young male patients are lacking. The purpose of this study was to retrospectively compare the characteristics of men and women who underwent the DelormeThiersch procedure, and to analyze the postoperative outcomes to evaluate the usefulness of the perineal approach by sex.

\section{METHODS}

The study's protocol was reviewed and approved by the Institutional Review Board of Seoul Song Do Colorectal Hospital (approval number: 2018-007) and was eligible for exemption from informed consent. From January 2011 to September 2017, 592 patients with rectal prolapse underwent surgery at Seoul Song Do Colorectal Hospital in Korea. Among them, 293 patients who underwent the Delorme-Thiersch procedure were enrolled. All surgeries were performed by 2 experienced surgeons. Patient diagnoses were confirmed by clinical examinations and defecographies. Demographic data, medical histories, surgical findings, and patient follow-up details were recorded. Fecal incontinence was assessed with questionnaires such as the Cleveland Clinic Incontinence Score (CCIS, Wexner score), the fecal incontinence severity index (FISI), and the fecal incontinence quality of life (FIQOL) scale. All patients underwent preoperative colonoscopy to exclude intraluminal pathology, as well as anal manometry and pudendal nerve terminal motor latency (PNTML) testing to evaluate anorectal physiology. Patients were evaluated for surgical risk with preoperative blood testing, cardio-pulmonary function testing, and L-spine X-rays.

The patients were evaluated at 2 weeks and then re-evaluated with physical examination at 3-4 months postoperatively to identify postoperative complications and recurrences. Defecation proctography and fecal incontinence questionnaires including, the CCIS, FISI, and FIQOL scale, were performed.

Quantitative data are expressed as the median and range, and statistical analyses were performed using the paired t-test for paired data. A P-value of $<0.05$ was considered statistically significant.

\section{RESULTS}

Between January 2011 and September 2017, 293 patients underwent the Delorme-Thiersch procedure. No intraoperative complications or postoperative mortalities were reported. There were 111 male patients (37.88\%) and 182 female patients $(62.12 \%)$. The mean age of all patients was $70.24 \pm 1.03$ years. The male patients were younger in age than the female patients $(59.07 \pm 18.66$ years vs. $77.05 \pm 13.17$ years, $\mathrm{P}<0.001)$. In total, $44.14 \%$ of the male patients were younger than 60 years of age and $92.31 \%$ of the female patients were older than 60 years of age (Fig. 1).

Incontinence was the most common symptom in both sexes and constipation was the second most common. Pain was the only symptom that showed a statistically significant difference. Analysis of patient bowel habits was consistent with previous studies in which male patients were often affected by obstructive symptoms. Preoperatively, about $40 \%$ of the male patients took 10 minutes or more for defecation (Table 1).

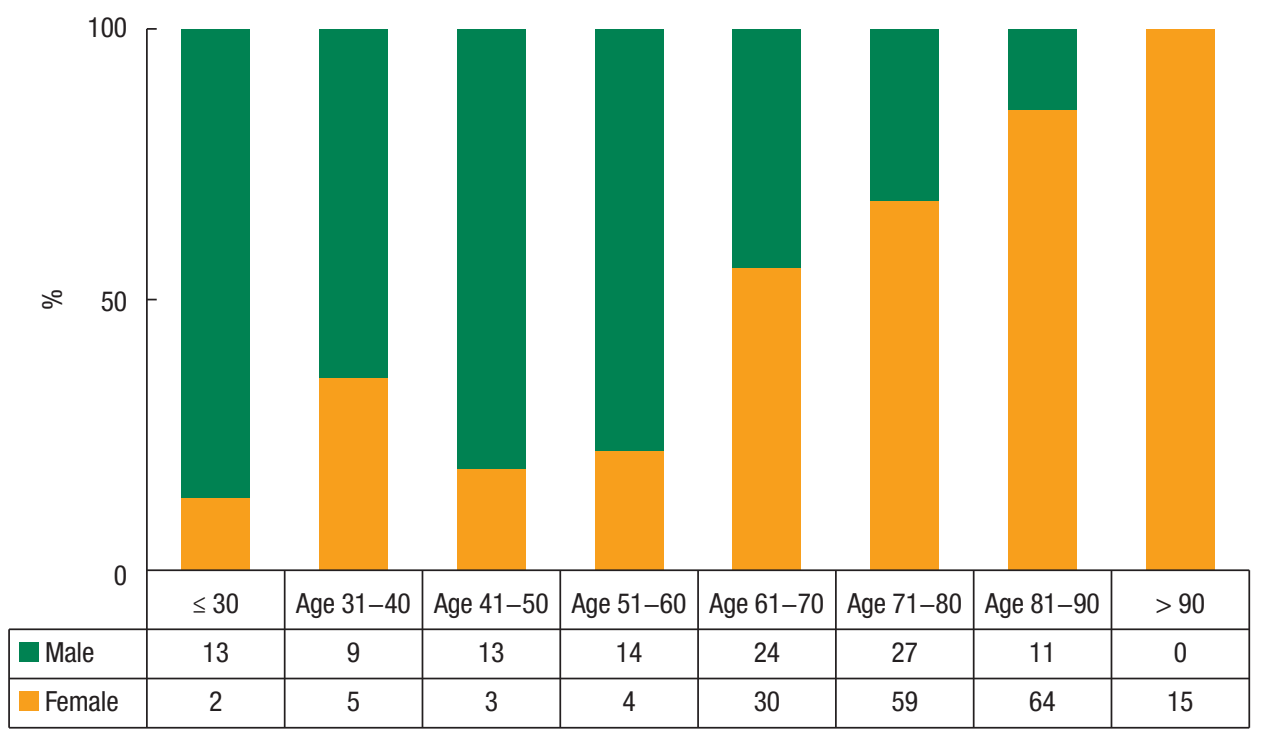

Fig. 1. In the $100 \%$ stacked column graph, almost all patients under 60 years of age were men, and almost all over 60 years of age were women. 


\section{Coloproctology}

Table 1. Patient characteristics

\begin{tabular}{lcccc}
\hline Characteristic & Total $(\mathrm{n}=239)$ & Men $(\mathrm{n}=111)$ & Women $(\mathrm{n}=182)$ & P-value \\
\hline Age $(\mathrm{yr})$ & $70.24 \pm 17.98$ & $59.07 \pm 18.66$ & $77.05 \pm 13.17$ & 0.001 \\
BMl $\left(\mathrm{kg} / \mathrm{m}^{2}\right)$ & $23.46 \pm 1.22$ & $23.98 \pm 3.22$ & $22.76 \pm 4.49$ & 0.350 \\
ASA PS classification & $2.20 \pm 0.16$ & $2.04 \pm 0.35$ & & \\
Chief complaint & & & & \\
$\quad$ Incontinence & $107(36.52)$ & $34(30.63)$ & $70(38.46)$ & 0.005 \\
Constipation & $77(26.28)$ & $27(24.32)$ & $50(27.47)$ & 0.174 \\
Bleeding & $50(17.06)$ & $20(18.02)$ & $30(16.48)$ & 0.553 \\
Discharge & $39(13.31)$ & $17(15.32)$ & $22(12.09)$ & 0.735 \\
Pain & $51(17.41)$ & $9(8.11)$ & $42(23.08)$ & 0.430 \\
Tenesmus & $35(11.95)$ & $15(13.51)$ & $20(10.99)$ & 0.001 \\
Defecation time (min) & & $38(60.32)$ & & 0.518 \\
$<10$ & 94 & $25(39.68)$ & $56(76.71)$ & $17(23.29)$ \\
$\geq 10$ & 42 & & \\
\hline
\end{tabular}

Values are presented as mean \pm standard deviation or number (\%).

BMI, body mass index; ASA PS, American Society of Anesthesiologists physical status.

Table 2. Underlying disease and surgical history of the study patients.

\begin{tabular}{lccc}
\hline Variable & Men $(\mathrm{n}=111)$ & Women $(\mathrm{n}=182)$ & P-value \\
\hline Underlying disease & & & \\
Disc herniation, spinal disease & $21(18.92)$ & $53(29.12)$ & 0.051 \\
Hypertension & $25(22.52)$ & $100(54.95)$ & 0.001 \\
Diabetes & $12(10.81)$ & $34(18.68)$ & 0.072 \\
Cardiovascular & $13(11.71)$ & $34(18.68)$ & 0.115 \\
Pulmonary & $7(6.31)$ & $7(3.85)$ & 0.338 \\
Psychiatric & $7(6.31)$ & $10(5.49)$ & 0.773 \\
Proctology/hemorrhoids & $21(18.92)$ & $24(13.19)$ & 0.187 \\
\hline Rectal prolapse & $22(19.82)$ & $46(25.27)$ & 0.283 \\
Pelvic floor disorder & - & $35(19.23)$ & \\
Other & $27(24.32)$ & $39(21.43)$ & 0.565 \\
Surgical history & & & \\
Spinal surgery & $14(12.61)$ & $37(20.33)$ & 0.091 \\
\hline Proctology & $21(18.92)$ & $24(13.19)$ & 0.187 \\
\hline Abdominal surgery & $16(14.41)$ & $21(11.54)$ & 0.472 \\
\hline Rectal prolapse & $22(19.82)$ & $46(25.27)$ & 0.283 \\
\hline Hysterectomy and other & - & $56(30.77)$ & \\
pelvic floor operations & & $13(7.14)$ & 0.001 \\
\hline Other & $26(23.42)$ & & \\
\hline
\end{tabular}

Values are presented as number (\%).

The most common underlying disease was hypertension (men: 26 of 111; women: 100 of 182). The second most common disorder was spinal disease. Congenital diseases such as mental retar-
Table 3. Preoperative evaluation and anorectal function testing

\begin{tabular}{lccc}
\hline Variable & Male & Female & P-value \\
\hline L-spine X-ray & $43 / 96(45.3)$ & $140 / 176(79.5)$ & 0.001 \\
Manometry pressure $(\mathrm{mmHg})$ & & & \\
$\quad$ At resting & $40.08 \pm 16.12$ & $30.22 \pm 13.74$ & 0.001 \\
At squeezing & $105.46 \pm 56.06$ & $55.48 \pm 28.14$ & 0.001 \\
PNTML abnormality & $6 / 21(28.6)$ & $25 / 43(58.1)$ & 0.001 \\
Right : left : both & $2: 2: 2$ & $6: 7: 12$ & \\
\hline
\end{tabular}

Values are presented as number (\%) or mean \pm standard deviation.

PNTML, pudendal nerve terminal motor latency.

dation and autism in male patients were not significantly different from those in female patients. Of the 119 female patients with recorded parity information, the mean parity was 3.59. Among 182 female patients, 37 (20.33\%) had previous spinal operation, 19 had previous hysterectomy, and 10 had other operations for pelvic floor disorders such as urinary incontinence (Table 2).

In preoperative examination, female patients had more abnormal findings on L-spine X-rays compared with male patients, and their anal pressures were significantly lower. Male patients had relatively better anorectal function than female patients (Table 3 ). The operative times were longer and postoperative bleeding was more frequent in men than in women. Complications, including severe complications such as rectal perforation, were more frequent in male patients. The duration of hospitalization for male patients was longer, which was probably due to more pain complaints (Table 4).

The mean follow-up period was 12.22 months. Fecal incontinence scores improved in the women, but not in the men. The 
Table 4. Operative findings and postoperative results

\begin{tabular}{lccc}
\hline Variable & Men & Women & P-value \\
\hline Mean section size (cm) & 10.28 & 9.91 & 0.210 \\
Mean operative time (min) & 59.89 & 50.55 & 0.001 \\
Complications & $23 / 111(20.7)$ & $14 / 182(7.7)$ & 0.001 \\
\hline T ring infection & 8 & 7 & \\
Postoperative bleeding & 6 & 3 & \\
Stricture & 3 & 1 & \\
Severe pain & 2 & 1 & \\
Rectal perforations (stoma) & 2 & & \\
\hline Other & 2 & 2 & 0.004 \\
Mean hospital stay (day) & 6.42 & 5.73 & 0.012 \\
Recurrence & $3 / 111(2.7)$ & $20 / 162(11.0)$ & 0.063 \\
Postoperative constipation & $13 / 90(14.4)$ & $31 / 125(24.8)$ & 0.550 \\
Satisfaction score (0-10) & $9.17 \pm 0.80$ & $9.15 \pm 0.39$ & \\
Fecal incontinence score: & & & 0.024 \\
Wexner score & & & \\
\hline Preoperative & $9.25 \pm 2.65$ & $12.08 \pm 1.42$ & \\
\hline Postoperative & $9.57 \pm 3.21$ & $7.46 \pm 6.78$ & \\
\hline FISI score & & & 0.017 \\
\hline Preoperative & $28.62 \pm 8.27$ & $38.91 \pm 3.58$ & \\
\hline Postoperative & $29.26 \pm 8.01$ & $20.60 \pm 4.23$ & \\
\hline FIQ0L score & & & \\
$\quad$ Preoperative & $15.12 \pm 4.57$ & $11.14 \pm 4.85$ & \\
\hline Postoperative & $12.88 \pm 4.79$ & $13.82 \pm 1.30$ & \\
\hline
\end{tabular}

Values are presented as number (\%) or mean \pm standard deviation unless otherwise indicated.

FISI, fecal incontinence severity index; FIQOL, fecal incontinence quality of life.

overall recurrence rate was $7.8 \%$ ( 23 of 293 ), and was $2.7 \%$ for men and $11.0 \%$ for women (Table 4 ).

\section{DISCUSSION}

The treatment for rectal prolapse is surgery. With the introduction of laparoscopic surgery, new developments have been made for the treatment of rectal prolapse. The ventral rectopexy method is a procedure that is easy to learn and can be used for midcompartment prolapse. It has received positive attention from pelvic floor surgeons, especially those in Europe [8]. However, because ventral rectopexy leaves a permanent mesh on the rectovesical or rectovaginal septum, it can be highly problematic for young patients who need to preserve fertility $[9,10]$. For this reason, attempts have been made to use biologic materials, but the evidence for safety is still lacking $[11,12]$. As a result of our retrospective analysis, we found that male patients undergoing the DelormeThiersch procedure were younger, had better preserved anorectal function, and had a relatively small number of spinal diseases compared with female patients. In contrast, the female patients tended to be older, and their rectal prolapse tended to be related to degenerative anorectal changes, histories of birth trauma, and spinal neuropathies.

The purpose of this study was to evaluate the usefulness of the Delorme-Thiersch operation. Among the patients in this study, $37.88 \%$ were men. The percentage of male patients under the age of 60 years who needed to preserve fertility was nearly half of the male patients (44.14\% of male patients and $17 \%$ of total 293 female and male patients). While these results are consistent with previous Korean studies, these results are different from Western data showing that the majority of patients were women [7]. The reason for the high number of young male patients in Korea or East Asia is not yet clear. Some reports suggest that congenital disabilities were more associated with young patients [13, 14], but this was not related to our study. Future research on the pathogenesis is needed.

The Delorme-Thiersch operation is advantageous in preserving fertility because there is no mesh placed in the pelvic cavity, which is associated with less nerve damage. The Delorme surgery was first described by the French military surgeon Edmond Delorme in 1900 [15]. It involves mucosal and submucosal dissection, plication of the remaining muscle layer, and mucosal anastomosis. Thiersch first reported a technique of anal encirclement in 1891, which provided a physical barrier that restricted the anal lumen size to prevent further prolapse [16]. Anal encirclement alone is associated with a high recurrence rate and fecal impaction can occur after surgery because the prolapsed rectum remains in place. Thiersch surgery alone has been used for a limited number of patients with very high operative risk $[17,18]$. The combined Delorme-Thiersch procedure removes the bundle of the rectum through the Delorme's procedure and corrects the patulous anus by Thiersch encirclement to prevent recurrence.

Although the conventional Delorme-alone or Thiersch-alone techniques showed high recurrence rates of $15 \%-30 \%[6,19]$, the results of this Delorme-Thiersch combined study showed a low recurrence rate of $7.8 \%$, which was much lower in male patients (2.7\%) than in female patients. There are several hypotheses as to why this may occur. The male patients with rectal prolapse were younger, healthier, and had relatively better anorectal function than the female patients in this study. Many female patients complained of dull pain and heaviness in the anorectum. This is thought to be related to the greater incidence of spinal diseases in elderly women. Among the female patients, $29.12 \%$ had spinal diseases and $20.33 \%$ had a history of spinal surgery. This is much higher than the $7.12 \%$ incidence of disc herniation operation in adults aged $>70$ years, according to a survey by the National Health Insurance of Korea in 2015. There are few reports of direct association between rectal prolapse and spinal disease. However, patients with spinal cord injuries can have gastrointestinal problems such as difficulty with bowel evacuation [20]. In addition, 
Table 5. Comparison of manometry

\begin{tabular}{|c|c|c|c|c|c|c|}
\hline \multirow[b]{2}{*}{ Variable } & \multicolumn{2}{|c|}{ 21-50 Years } & \multicolumn{2}{|c|}{$51-70$ Years } & \multicolumn{2}{|c|}{ Over 70 Years } \\
\hline & $\begin{array}{l}\text { Resting } \\
(\mathrm{mmHg})\end{array}$ & $\begin{array}{c}\text { Squeezing } \\
(\mathrm{mmHg})\end{array}$ & $\begin{array}{l}\text { Resting } \\
(\mathrm{mmHg})\end{array}$ & $\begin{array}{c}\text { Squeezing } \\
(\mathrm{mmHg})\end{array}$ & $\begin{array}{l}\text { Resting } \\
(\mathrm{mmHg})\end{array}$ & $\begin{array}{c}\text { Squeezing } \\
(\mathrm{mmHg})\end{array}$ \\
\hline \multicolumn{7}{|l|}{ Men } \\
\hline Control $^{\mathrm{a}}$ & 79.63 & 158.97 & 74.7 & 154.93 & 63.03 & 137.1 \\
\hline Prolapse & $\begin{array}{c}44.45 \\
(55.81 \%)\end{array}$ & $\begin{array}{c}107.47 \\
(67.58 \%)\end{array}$ & $\begin{array}{c}40.36 \\
(54.04 \%)\end{array}$ & $\begin{array}{c}118.79 \\
(76.67 \%)\end{array}$ & $\begin{array}{c}34.35 \\
(54.50 \%)\end{array}$ & $\begin{array}{c}94.19 \\
(68.70 \%)\end{array}$ \\
\hline \multicolumn{7}{|l|}{ Women } \\
\hline Control & 71.07 & 117.83 & 64.43 & 108.77 & 59.63 & 95.47 \\
\hline Prolapse & $\begin{array}{c}35.70 \\
(50.24 \%)\end{array}$ & $\begin{array}{c}64.80 \\
(54.99 \%)\end{array}$ & $\begin{array}{c}34.76 \\
(53.95 \%)\end{array}$ & $\begin{array}{c}64.41 \\
(59.22 \%)\end{array}$ & $\begin{array}{c}28.67 \\
(48.08 \%)\end{array}$ & $\begin{array}{c}52.54 \\
(55.04 \%)\end{array}$ \\
\hline
\end{tabular}

Each control group included 30 patients of the same age with other anorectal diseases in our clinic during the same period. In both men and women, sphincter pressures decreased in the patients with rectal prolapse compared to the control group. In male patients, the squeezing pressure was maintained at 70\% compared with the control group, while the squeezing pressure was maintained $50 \%$ in female patients.

${ }^{a}$ Control $=30$ patients with hemorrhoids, fissure, fistula.

solitary rectal ulcer syndrome was found in patients with spinal cord injury [21]. Further research is needed on the pathophysiologic association of spinal disease that might cause rectal prolapse.

According to the manometry results, female patients had lower anal pressures than male patients. For a more detailed comparison, we compared manometry of patients in the same age group with other anorectal diseases. As a result, the squeezing pressure of female patients with rectal prolapse was about half that of other anorectal patients of the same age group (Table 5). There were also many female patients with PNTML abnormalities, and the mean parity number of our female patients was 3.59. Vaginal delivery is known to stretch the pudendal nerves, which can cause long-term neurological damage in perineal descent, prolapse, and incontinence [22]. Match analysis between these control groups and female rectal prolapse patients will be needed.

In this study, rectal prolapse in female patients was associated with degenerative changes, birth trauma, and spinal neuropathy. Correcting female rectal prolapse through a perineal approach without managing the accompanying pelvic floor weakness and/ or midcompartment prolapse is considered to be inadequate therapy. This suggests that a multidisciplinary approach to the accompanying degenerative change is needed in female patients. We recently reported on the simultaneous correction of rectal prolapse and midcompartment prolapse by a laparoscopic approach [23], which should be considered when treating patients with midcompartment prolapse.

In contrast, the male patients in our study were younger (the youngest was 19 years), had better preserved anorectal function, and a relatively small number of spinal diseases. Thus, there is no additional downward pressure contributing to prolapse in male patients after the Delorme-Thiersch operation. During surgery, male patient rectums were tightly attached and hard to dissect. The mesorectum of the male patients tended to be healthy and bulky. After excising the prolapsed rectal tissues, the pelvic outlet was filled with the mesorectum and no further escape occurred. In older female patients, the rectal attachments were loose and there was shrinkage of the mesorectum compared with younger male patients. In addition, the pelvic outlets tended to be wider due to the possibility of prior birth trauma. Therefore, even after the Thiersch encirclement, we believe that the pelvic outlets seemed to have a lot of empty space with persistent downward pressure, which increased the likelihood of bowel prolapse. For this reason, it would be beneficial to perform fixation using an abdominal approach in multiparous women with midcompartment pathology.

Recurrence rate in male patients was low, but the incidence of complications was high. Compared to the redundant bowel in female patients, the male rectal attachments were difficult to dissect, which increased the operative times and predisposed them to complications, including postoperative bleeding, rectal perforation, and stricture. There were many cases of postoperative pain that required intravenous pain control, and the length of hospital stays was long. Although accurate investigations were not recorded, there were many complaints of pain during the outpatient visits. Therefore, detailed consultation with the patient is essential prior to performing the Delorme-Thiersch operation. Although the recurrence rate is low and the absence of mesh, which could irritate the pelvic cavity, is favorable for preserving fertility, education and preparation are needed because of the high rate of complications.

To the best of our knowledge, the present study provides an analysis of the largest number of Delorme-Thiersch operations performed to treat patients with rectal prolapse in a single healthcare facility. However, the follow-up period was relatively short. Further study on the pathophysiology with long-term follow-up is needed. To determine the usefulness of tailored management, it is necessary to compare patients who decided upon surgery based on this strategy with those who did not. Therefore, a long-term follow-up study comparing the laparoscopic versus the perineal approach in young male patients or older female patients is needed.

\section{CONFLICT OF INTEREST}

No potential conflict of interest relevant to this article was reported.

\section{REFERENCES}

1. Yoon SG. Rectal prolapse: review according to the personal experience. J Korean Soc Coloproctol 2011;27:107-13.

2. Melton GB, Kwaan MR. Rectal prolapse. Surg Clin North Am 2013;93:187-98.

3. Berman IR. Sutureless laparoscopic rectopexy for procidentia. 
Technique and implications. Dis Colon Rectum 1992;35:689-93.

4. Tou S, Brown SR, Nelson RL. Surgery for complete (full-thickness) rectal prolapse in adults. Cochrane Database Syst Rev 2015; CD001758.

5. Young MT, Jafari MD, Phelan MJ, Stamos MJ, Mills S, Pigazzi A, et al. Surgical treatments for rectal prolapse: how does a perineal approach compare in the laparoscopic era? Surg Endosc 2015;29: 607-13.

6. Senapati A, Gray RG, Middleton LJ, Harding J, Hills RK, Armitage NC, et al. PROSPER: a randomised comparison of surgical treatments for rectal prolapse. Colorectal Dis 2013;15:858-68.

7. Yoon SG, Lee KR, Cho KA, Hwang DY, Kim KU, Kang YW, et al. Clinical and physiologic characteristics of rectal prolapse in males. J Korean Soc Coloproctol 2000;16:223-30.

8. D’Hoore A, Cadoni R, Penninckx F. Long-term outcome of laparoscopic ventral rectopexy for total rectal prolapse. Br J Surg 2004; 91:1500-5

9. Siddika A, Saha S, Siddiqi S. Evolution of male rectal prolapse surgery and initial experience of robotic rectopexy in men. J Robot Surg 2017;11:311-6.

10. Badrek-Al Amoudi AH, Greenslade GL, Dixon AR. How to deal with complications after laparoscopic ventral mesh rectopexy: lessons learnt from a tertiary referral centre. Colorectal Dis 2013;15: 707-12.

11. Albayati S, Morgan MJ, Turner CE. Laparoscopic ventral rectopexy for rectal prolapse and rectal intussusception using a biological mesh. Colorectal Dis 2017;19:857-62.

12. Fu CW, Stevenson AR. Risk factors for recurrence after laparoscopic ventral rectopexy. Dis Colon Rectum 2017;60:178-86.

13. Van Heest R, Jones S, Giacomantonio M. Rectal prolapse in autistic children. J Pediatr Surg 2004;39:643-4.
14. Shah A, Parikh D, Jawaheer G, Gornall P. Persistent rectal prolapse in children: sclerotherapy and surgical management. Pediatr Surg Int 2005;21:270-3.

15. Classic articles in colonic and rectal surgery. Edmond Delorme 1847-1929. On the treatment of total prolapse of the rectum by excision of the rectal mucous membranes or recto-colic. Dis Colon Rectum 1985;28:544-53.

16. Thiersch C. Carl Thiersch 1822-1895. Concerning prolapse of the rectum with special emphasis on the operation by Thiersch. Dis Colon Rectum 1988;31:154-5.

17. Dietzen CD, Pemberton JH. Perineal approaches for the treatment of complete rectal prolapse. Neth J Surg 1989;41:140-4.

18. Devesa JM, Vicente R. The use of a simple anal sling in the management of anal incontinence. Gastroenterol Rep (Oxf) 2014;2:1369.

19. Emile SH, Elfeki H, Shalaby M, Sakr A, Sileri P, Wexner SD. Perineal resectional procedures for the treatment of complete rectal prolapse: A systematic review of the literature. Int J Surg 2017;46:14654.

20. Stone JM, Nino-Murcia M, Wolfe VA, Perkash I. Chronic gastrointestinal problems in spinal cord injury patients: a prospective analysis. Am J Gastroenterol 1990;85:1114-9.

21. Wang F, Frisbie JH, Klein MA. Solitary rectal ulcer syndrome (colitis cystica profunda) in spinal cord injury patients: 3 case reports. Arch Phys Med Rehabil 2001;82:260-1.

22. Henry MM, Parks AG, Swash M. The pelvic floor musculature in the descending perineum syndrome. Br J Surg 1982;69:470-2.

23. Yang SJ, Yoon SG, Lim KY, Lee JK. Laparoscopic vaginal suspension and rectopexy for rectal prolapse. Ann Coloproctol 2017;33: 64-9. 